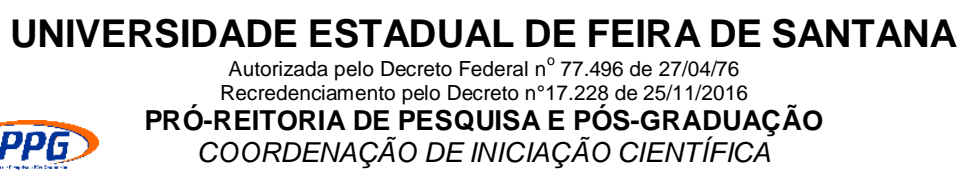

XXIII SEMINÁRIO DE INICIAÇÃO CIENTÍFICA DA UEFS

SEMANA NACIONAL DE CIENTÍFICA E TECNOLÓGICA - 2019

\title{
Biblioteca espectral como suporte a inventários de ocorrências minerais para conhecimento da Geodiversidade na Bacia de Campinas, estado da Bahia.
}

\section{SILVA, Ericka M. ${ }^{1}$; FRANCA-ROCHA, Washington de J. S. ${ }^{2}$; SOUZA, Deorgia T. M. ${ }^{3}$.}

1. Bolsista PROBIC/UEFS, Graduanda em Licenciatura em Geografia, Universidade Estadual de Feira de Santana, email: medeirosericka05@gmail.com

2. Orientador, Departamento de Ciências Exatas, Universidade Estadual de Feira de Santana, e-mail: wrocha@uefs.com

3. Co-orientadora, Departamento de Ciências Exatas, Universidade Estadual de Feira de Santana, e-mail: deorgiasouza.geo@gmail.com

PALAVRAS-CHAVE: Espectrorradiometria; Sensoriamento Remoto; Recursos Minerais.

\section{INTRODUÇÃO}

O Sensoriamento Remoto tem sido cada vez mais utilizado no conhecimento das ciências da Terra, para caracterização e interpretação de alvos na superfície terrestre, como na prospecção mineral a partir da espectrorradiometria. Neste caso, a ferramenta visa a discriminação espectral de alvos específicos, a partir da sua curva espectral de reflectância, produzida com base nos processos eletrônicos e vibracionais resultantes da interação entre a energia com os átomos que formam os minerais. E da combinação dos espectros dos diferentes minerais, formam a assinatura espectral de uma rocha. (BINOTTO, 2015).

As curvas espectrais de reflectância dos minerais exibem feições diagnósticas em diferentes comprimentos de onda que permitem a discriminação e identificação de alvos que podem estar em áreas potenciais para a exploração mineral, permitindo a redução do custo e tempo na exploração (LIMA et al., 2005).

O estado da Bahia possui um vasto patrimônio geológico que precisa ser conhecido e preservado. Este trabalho tem o objetivo de elaborar uma biblioteca de padrões espectrais como suporte a inventários de ocorrências minerais para conhecimento da Geodiversidade na Bacia de Campinas, no estado da Bahia, de forma que crie um banco de dados que contribua para consultas internas e externas de pesquisadores, empresários, estudantes e demais interessados de áreas afins, dando suporte a outras pesquisas de caráter mineralógico.

\section{MATERIAL E MÉTODOS OU METODOLOGIA}


Utilizou-se uma coleção de 27 dados espectrais neste estudo, obtidos in situ e em amostras de solos e rochas coletadas nos principais distritos da área de estudo desta pesquisa, pela equipe do projeto Mapa Metalogenético II, sendo 22 espectros de rochas carbonáticas calcárias e dolomíticas e 5 espectros de solos, coletados nos municípios de Morro do Chapéu, Várzea Nova e Jacobina.

As medidas espectrorradiométricas das amostras de rochas e solos foram obtidas com um Espectrorradiômetro portátil, produzida pela ASD (Analytical Spectral Devices, inc.). Em seguida empregou-se softwares específicos, a exemplo do $\mathrm{RS}^{3} \mathrm{e}$ ViewSpec Pro, para o tratamento dos dados espectrais.

As medidas espectrais foram catalogadas, com georreferênciamento e descrições geológicas, e posteriormente, para interpretação e avaliação utilizou-se o software ENVI, permitindo a visualização/comparação das curvas espectrais, aplicação da técnica de contínuo removido e elaboração de bibliotecas espectrais, além de comparar com assinaturas espectrais de minerais da biblioteca de referência da USGS (Digital Spectral Library) como procedimento de validação.

A elaboração da biblioteca espectral com as amostras de solos e rochas está baseada em particularidades entre elas, ou seja, foram agrupadas em padrões a partir das bandas de absorção, em sintonia de composição química e constituições mineralógicas presentes.

\section{RESULTADOS E/OU DISCUSSÃO}

Os espectros de rochas são definidos, principalmente, pela sua composição mineralógica, o qual, muitas vezes possuem as absorções características dos seus minerais predominantes. Nas rochas carbonáticas, as suas absorções características se concentram entre $\sim 2300$ e $\sim 2350 \mathrm{~nm}$, correspondente a presença do íon $\mathrm{CO}_{3}{ }^{2-}$ (MENESES \& ALMEIDA, 2019).

Dentre os espectros das amostras, além da absorção característica dos carbonatos, pode ser observado nos espectros frequentes absorções na faixa do SWIR, em $\sim 1400 \mathrm{~nm}$ e $\sim 1900 \mathrm{~nm}$, indicando a presença do grupo hidroxila e água, respectivamente. Segundo Meneses e Almeida (2019), qualquer indício dessas absorções em rochas carbonáticas significa, no mínimo, a existência de impurezas. Além delas, as bandas de Al-OH, entre $\sim 2160 \mathrm{~nm}$ e $\sim 2200 \mathrm{~nm}$ aparecem com regularidade. E no VNIR, são frequentes as absorções características da presença de ferro no sistema. No comportamento espectral dos solos foi possível observar, através das absorções, a presença de argilominerais, em função das absorções na faixa de 1400 $\mathrm{nm}, \sim 1900 \mathrm{~nm}$ e $\sim 2200 \mathrm{~nm}$, e a presença de óxidos de ferro expressos na região do visível.

Foram identificados a partir das bandas de absorção seis padrões espectrais de rochas e com as cinco amostra de solos foi constatado um único padrão de absorção (figura 1).

No padrão espectral exibido na figura $1 \mathrm{~A}$, presume-se a presença da calcita na composição da amostra, devido a absorção similar ao espectro da calcita da USGS em $\sim 2338 \mathrm{~nm}$, indicativo do íon $\mathrm{CO}_{3}{ }^{2-}$. Além dela, identifica-se a montmorilonita nas amostras 7, 80 e 84, pelas feições em $\sim 1415 \mathrm{~nm}, \sim 1913 \mathrm{~nm}$ e $\sim 2209 \mathrm{~nm}$, e a goethita pelas feições de absorção na região do visível (VNIR) referente ao Fe. Já nos espectros da figura $1 \mathrm{~B}$, as absorções na região do SWIR, a partir de $\sim 1600 \mathrm{~nm}$, são similares ao espectro da calcita. Nota-se também a presença da goethita com as feições de absorção 
na região do VNIR, nas amostras 06_(1) e 102, devido a presença de Fe em sua composição.

Na figura $1 \mathrm{C}$, pelas feições de absorção dos espectros, identifica-se a presença da calcita na composição das amostras e, nas amostras 11_1 e 14_(B), a montmorilonita, pelas absorções decorrentes das moléculas de $\mathrm{OH}$, da água e Al-OH.

Nos espectros da figura $1 \mathrm{D}$, as feições de absorção apresentadas a partir de $\sim 1600 \mathrm{~nm}$, em $\sim 1862 \mathrm{~nm}, \sim 1927 \mathrm{~nm}, \sim 2140 \mathrm{~nm}, 2320 \mathrm{~nm}$ e $\sim 2498 \mathrm{~nm}$, são diagnósticas do mineral dolomita. Assim como nos espectros do padrão da figura $1 \mathrm{E}$, nas amostras 10 e 25. A amostra 26_A, apesar de similar absorção, ela apresenta-se com um deslocamento de $10 \mathrm{~nm}$ para a direita, característico da calcita em relação à dolomita (MENESES \& ALMEIDA, 2019). Nesse padrão 1 D, é constatado também a presença da goethita.

Nos espectros exibidos na figura $1 \mathrm{~F}$, identificou-se a presença da calcita pela absorção centrada em $2335 \mathrm{~nm}$, exceto na amostra 26_B que apresenta-se com um deslocamento para esquerda, típico da dolomita, e ambas são resultantes do íon $\mathrm{CO}_{3}{ }^{2-}$.

No padrão espectral de solos, da figura $1 \mathrm{G}$, os espectros de solo absorvem na faixa de $\sim 400-490 \mathrm{~nm}$ e $\sim 891 \mathrm{~nm}$. Absorções nessa faixa do espectro, de $350-1000$ $\mathrm{nm}$, são decorrentes da interação eletromagnética com os óxidos e hidróxidos de ferro, como da hematita e goethita (MESQUITA, 2018). De acordo a Meneses e Almeida (2019), a predominância de um ou outro mineral está relacionada geralmente a fatores pedohídricos, predominando a hematita em ambientes mais secos. No SWIR, ocorre absorções centradas em $\sim 1414 \mathrm{~nm}, \sim 1916 \mathrm{~nm}$, devido a vibrações fundamentais do grupo $\mathrm{OH}$ e da água, e em $\sim 2207 \mathrm{~nm}$, relacionado a ligação Al-OH. Outras absorções menos intensas ocorrem em $\sim 2312 \mathrm{~nm}, \sim 2354 \mathrm{~nm}$ e $\sim 2378 \mathrm{~nm}$, similares as do espectro de caulinita da USGS. As absorções intensas, agudas e simples nas faixas de $\sim 1400 \mathrm{~nm}$ $\sim 1900$ nm, 2220 são característicos de argilominerais montmorilonita. Já a ocorrência de absorções intensas, agudas e dupla em $\sim 1400 \mathrm{~nm}$ e $\sim 1990 \mathrm{~nm}$ são típicas (MENESES \& ALMEIDA, 2019).
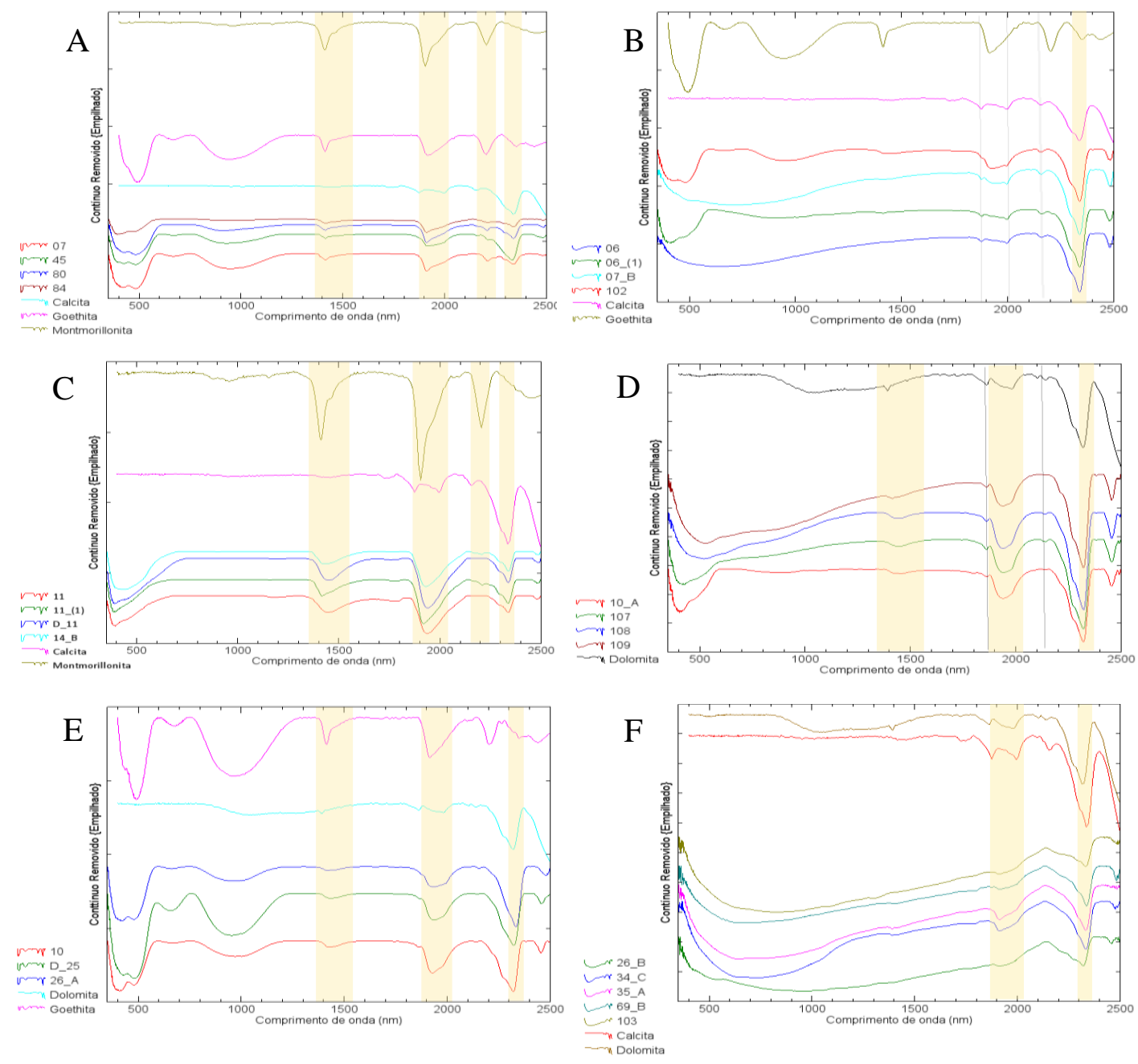


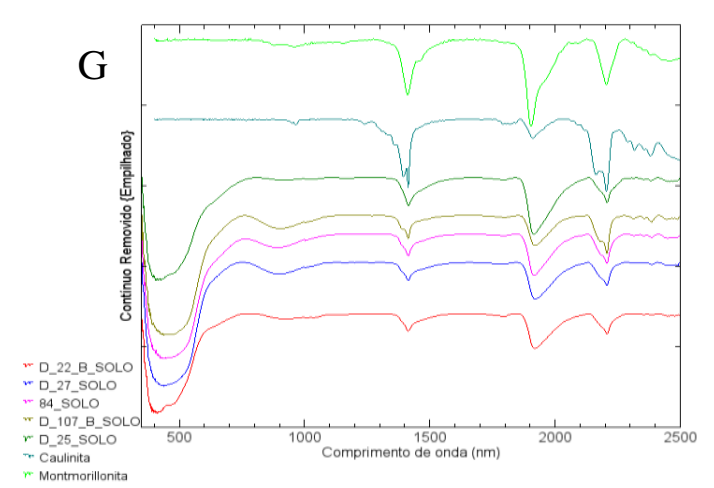

Figura 1- A, B, C, D, E e F - Assinaturas espectrais de amostras de rochas com espectros de minerais da USGS, através do método de remoção do contínuo; G - Assinaturas espectrais de amostras de solo e dos minerais caulinita e montmorilonita da USGS, através do método de remoção do contínuo. Fonte: autora (2019).

\section{CONSIDERAÇÕES FINAIS}

Diante dos resultados apresentados, as amostras se agruparam em diferentes padrões espectrais devido a variações de composição, como no teor de impurezas que se expressam pela presença dos argilominerais, óxidos e hidróxidos de ferro, comuns de serem encontradas em rochas carbonáticas.

No entanto, sendo rochas carbonáticas, com características comuns em sua composição, espectralmente todas apresentam as bandas diagnósticas do $\mathrm{CO}_{3}{ }^{2-}$ na faixa entre $2300 \mathrm{~nm}$ e $2350 \mathrm{~nm}$, e quanto mais similares os seus espectros ao mineral que predominantemente constitui esse litotipo (calcita e/ou dolomita), maior é o grau de pureza, como foi observado no padrão da figura $1 \mathrm{~B}$. Essas características diagnósticas das rochas carbonáticas tornam eficaz a criação das bibliotecas de padrões espectrais de ocorrência mineralógica para bacias sedimentares inseridas neste contexto, e com isso, servindo como suporte para inventários da geodiversidade da área em estudo.

\section{REFERÊNCIAS}

BINOTTO, R. B. Identificação de padrões espectrais em depósitos minerais: uma aplicação nas Minas de Camaquâ/RS, Brasil. Tese de Doutorado - UFRGS, Porto Alegre, RS, 2015. Disponível em: <http://rigeo.cprm.gov.br/xmlui/handle/doc/14799>. Acesso em: 10 out. 2018.

LIMA, B. E. M.; ALMEIDA FILHO, R.; GALVÃO, L. S.; MENESES, P. R. Avaliação das imagens do sensor ASTER para discriminação espectral de variações faciológicas no granito Serra Branca, Goiás. In: SIMPÓSIO BRASILEIRO DE SENSORIAMENTO REMOTO, 12, 2005, Goiânia. Anais... São José dos Campos: INPE, 2005. p.1815-1822.

MENESES, P. R; DE ALMEIDA, T. Refletância das Rochas. In: MENESES, P. R; DE ALMEIDA, T.; BAPTISTA, G. M. M. Reflectância dos materiais terrestres. Oficina de Textos, 2019.

MENESES, P. R; DE ALMEIDA, T. Refletância dos minerais. In: MENESES, P. R; DE ALMEIDA, T.; BAPTISTA, G. M. M. Reflectância dos materiais terrestres. Oficina de Textos, 2019.

MESQUITA, F. F. de. Caracterização espectrorradiometrica de solos para a determinação da evolução pedogenética dos regolitos da região de Alvorada do Norte, Goiais. 2018. 31 f. TCC (Graduação) - Curso de Geoprocessamento Ambiental, Instituto de Geociências, Universidade de Brasília, Brasília, 2018. Disponível em: <bdm.unb.br/bitstream/10483/22147/1/2018_FilipyFerreiraDeMesquita_tcc.pdf>.

Acesso em: 18 abr. 2019. 